\title{
QUALIDADE E TRABALHO DOCENTE: AS EXPERIÊNCIAS E OPORTUNIDADES DE APRENDIZAGEM DOS PROFESSORES
}

\author{
ROSALINDA HERDEIRO* \\ ANA MARIA SILVA*
}

\begin{abstract}
RESUMO: Este artigo insere-se numa investigação levada a cabo em Portugal, cujo objectivo é compreender o impacto de legislação produzida recentemente com o objetivo expresso da melhoria da qualidade do trabalho docente, objetivo que se reflete nas oportunidades de aprendizagem dos professores e na sua identidade profissional. No texto evidenciamos alguns resultados decorrentes da análise de conteúdo efetuada com recurso ao programa NVivo, versão 9.0, à informação recolhida através de narrativas orais e escritas, grupos de discussão e às questões abertas de um questionário aplicado a 396 professores do $1^{\circ}$ Ciclo do Ensino Básico (CEB). Os resultados revelam que a qualidade do trabalho docente está comprometida pelo descontentamento profissional dos professores. Este descontentamento resulta, em grande medida, da ausência de reconhecimento, nomeadamente pelos superiores hierárquicos, cujos efeitos se refletem negativamente na identidade vivida pelos professores e na sua prática docente.
\end{abstract}

Palavras-chave: Trabalho docente. Qualidade. Oportunidades de aprendizagem. Experiências profissionais. Identidade profissional.

\section{TEACHING WORK AND QUALITY: TEACHERS' EXPERIENCES AND LEARNING OPPORTUNITIES}

ABSTRACT: This communication is part of a research project carried out in Portugal. Its main objective is to understand the impact of recent legislation - which aims at improving teachers' work quality - on aspects such as teachers' learning opportunities, the teaching career and the (re)construction of professional identity. In this text, we highlight some results of the analysis (performed with the help of the NVivo program version 9.0) of data obtained from oral and written narratives, discussion groups and an open-ended questionnaire given to 396 primary school teachers. The results reveal that the teaching work is compromised due to professional

\footnotetext{
* Universidade do Minho. Braga - Portugal.

* Universidade do Minho. Braga - Portugal.

Contato com as autoras: <rosalinda.herdeiro@gmail.com>
} 
discontentment; discontentment resulting mostly from lack of recognition, mainly from their hierarchic superiors, which, in turn, has negative effects on the teachers' identity and their teaching practices.

Key words: Teaching work. Quality. Learning opportunities. Professional experiences. Professional identity.

\section{QuALITÉ DE L'ENSEIGNEMENT: LES EXPÉRIENCES}

\section{ET LES OPPORTUNITÉS D'APPRENTISSAGE DES ENSEIGNANTS}

RÉSUMÉ: Cet article s'insère dans une recherche prise en œuvre au Portugal, dont le principal l'objectif est de comprendre l'impact de la récente législation avec l'objectif d'améliorer la qualité du travail enseignant, objectif évidencé dans les opportunités d'apprentissage des enseignants et dans son identité professionnelle. Dans le texte nous prouvons quelques résultats obtenus à l'analyse de contenu effectuée avec ressource au programme NVivo, version 9.0, aux informations rassemblées à travers les récits oraux et écrits, groupes de discussion et aux questions ouvertes d'un questionnaire appliqué à 396 enseignants du 1er Cycle de l'Education de Base (CEB). Les résultats révèlent que la qualité du travail enseignant est compromise par le mécontentement professionnel des enseignants. Ce mécontentement résulte, dans une large mesure, de l'absence de reconnaissance, notamment par les supérieurs hiérarchiques, dont les effets se reflètent négativement dans l'identité vécue par les enseignants et dans leur pratique de l'enseignement.

Mots-clés: Travail enseignant. Qualité. Opportunités d'apprentissage. Expériences professionnelles. Identité professionnelle.

\section{Introdução}

A educação e a formação são pilares centrais de investimento, explicitamente reconhecidos como um domínio-chave prioritário da Estratégia de Lisboa, induzindo os governos europeus a uma intervenção política direccionada fundamentalmente para a qualidade da educação (MONTEIRO, 2008) e dos sistemas educativos nas diferentes vertentes que os constituem.

Assim, na visão política europeia, o termo qualidade é a categoria central do novo paradigma de educação sustentável, constituindo o horizonte de todas as iniciativas que se iniciam ou se reforçam.

Nesta perspectiva, a política das práticas de qualidade na educação e no ensino é reconhecida por uma grande parte de autores que têm vindo a estudar o seu impacto nas práticas docentes, como sendo decisões políticas que "desafiaram a autonomia profissional dos professores e levantaram a questão sobre o que significa ser um profissional sob um escrutínio público cada vez maior" (DAY, 2001, p. 21), despertando para a necessidade de os professores serem "bem formados, altamente 
motivados, com conhecimentos e capacitados, não apenas no início da sua carreira como também ao longo de todo o percurso profissional" (DAY; SACHS, 2004, p. 3).

Com efeito, em Portugal constatamos que a legislação recentemente emanada pelo Ministério da Educação veio desestabilizar o trabalho dos professores. Referimo-nos, especificamente, a dois documentos legais produzidos em Portugal na segunda metade da década passada: o novo Estatuto de Carreira Docente (Decreto-Lei n. 15/2007) e a Avaliação do Desempenho Docente (Decreto Regulamentar n. 2/2008).

Assim, em termos de promoção da qualidade do trabalho docente, o primeiro documento - Estatuto da Carreira Docente - pretende reforçar a importância de alguns aspetos, como a cooperação entre os professores, o papel e as funções das coordenações intermédias e a adopção de um corpo docente reconhecido, com mais experiência, mais autoridade e mais formação, que assegure a qualidade do ensino. Neste campo intencional, a avaliação do desempenho docente assume, na generalidade, um papel determinante na vida da escola, afectando, particularmente, a vida profissional e pessoal do professor.

Dessa forma, o segundo documento - Avaliação do Desempenho Docente visa, através desta avaliação, comprometer os professores com a melhoria dos resultados escolares dos alunos e da qualidade das suas aprendizagens, sustentadas num quadro de diferenciação profissional acompanhado por um sistema de quotas que determina o acesso e a progressão do professor na carreira docente.

Estes documentos foram marcos indeléveis para os professores e para o seu trabalho, sendo evidenciados, no estudo que realizámos, na identidade vivida (DUBAR, 1997) pelos professores com impacto nas suas experiências biográficas e relacionais (ibid.) resultantes, em grande medida, do conteúdo e intenções dos normativos anteriormente evocados, provocando um conjunto de experiências que denunciam frágeis e, com frequência, inexistentes oportunidades de aprendizagem, que podem comprometer a sua realização e desenvolvimento profissional e, consequentemente, a qualidade do trabalho docente.

\section{O trabalho docente e a qualidade do ensino}

Durante as últimas décadas, os principais desafios educativos assentavam na procura da qualidade educativa e na redescoberta da importância da aprendizagem na sala de aula (MARCHESI; MARTÍN, 2003).

Assim, se nos centrarmos nos recentes discursos políticos do campo educacional, tanto a nível internacional como nacional, apercebemo-nos de que o princípio da procura da qualidade educativa assume um lugar central e preponderante na resposta a um ensino com qualidade. 
Este princípio constitui-se como o horizonte de todas as iniciativas que se iniciam ou se reforçam, isto é, relaciona-se com a necessidade de proporcionar a todos os jovens uma educação mais completa e adaptada às demandas sociais.

Darling-Hammond (2010), tomando como referência o significado de um ensino eficaz, distingue dois contextos em que o termo qualidade é utilizado com maior frequência: a qualidade do ensino e a qualidade dos professores, conceitos muitas vezes confundidos pela sua aproximação, mas que, de facto, são distintos. Nesta perspectiva, para a autora, a qualidade do ensino "está associada a um ensino sólido, que permite a aprendizagem de uma grande diversidade de alunos e que vai ao encontro das exigências da disciplina, dos objectivos de aprendizagem e das necessidades dos alunos num determinado contexto" (p. 201). Em contrapartida, a qualidade dos professores, para além de ser uma dimensão da qualidade do ensino, pode ser definida como "um conjunto de características pessoais, de competências e de modos de compreensão que um indivíduo traz para o ensino, incluindo determinadas predisposições específicas em termos de comportamento" (p. 200).

Entretanto, o relatório da OCDE (1992, p. 208) refere que o termo qualidade "comporta diferentes significações que são ao mesmo tempo descritivas e normativas", estando na sua origem três razões: reacções a um período de crescimento, a reforma dos métodos de ensino e as solicitações económicas e sociais.

Os professores sofrem os efeitos da pressão política e das novas exigências, podendo atravessar uma crise de identidade profissional. Cada vez mais os docentes se sentem sobrecarregados de trabalho, experienciando vivências profissionais, de reconhecimento ou não reconhecimento do seu trabalho que marcam positiva ou negativamente o seu desenvolvimento profissional.

Nesta perspetiva, uma das estratégias para promover a qualidade do ensino e o desenvolvimento profissional dos professores é criar oportunidades de aprendizagem profissional na escola num ambiente colaborativo, estratégia que implica responsabilidade e empenho por parte de todos, mas particularmente dos órgãos de gestão, para que a qualidade (tanto do ensino como do professor) seja um propósito a alcançar.

Hargreaves (1998), referindo-se aos estudos de Lieberman e Miller (1984), acrescenta que o desenvolvimento do professor num contexto colaborativo conduz - para além da reflexão pessoal e idiossincrática, ou da dependência em relação a peritos externos - à aprendizagem dos professores em conjunto, partilhando e desenvolvendo as suas competências. Neste ambiente de partilha e de apoio colegial (HARGREAVES, op. cit.), a confiança e a interajuda entre os professores estimulam a experimentação na sala de aula/escola de novas práticas, numa perspectiva contínua de aperfeiçoamento do trabalho docente e da escola (HERDEIRO, 2010). 


\section{As experiências profissionais: identidade e desenvolvimento do professor}

$\mathrm{Na}$ actualidade, o professor assume um papel preponderante no processo de ensino e aprendizagem, sendo visto como um profissional que procura dar respostas às situações com que se depara, movendo-se muitas vezes em circunstâncias muito complexas e contraditórias que requerem a aprendizagem e a mobilização de competências específicas e um quadro de valores pessoais e profissionais considerados fundamentais no processo de mudança.

Dessa forma, a aprendizagem do professor assume um lugar de destaque no processo mutativo, desejando-se que seja contínua (DEAN, 1991), ao longo da carreira docente, com o objectivo de alcançar (ou manter) um patamar profissional de grande qualidade, tanto no domínio dos saberes científicos, quanto dos saberes pedagógicos. Para isso, são considerados determinados pré-requisitos, como: a certeza do tipo de aprendizagem que pretendemos; a definição clara de objectivos; o reconhecimento das características dos ambientes de trabalho e dos contextos e a identificação dos recursos existentes para a criação de oportunidades de aprendizagem impulsionadoras (SMYLIE, 1995).

Hargreaves e Fullan (1992, p. 1-2), partindo do pressuposto de que "oportunidades para aprender" implicam "oportunidades para ensinar" nas salas de aula - pensamento explorado por Woods (1990) na nota introdutória da sua obra Teacher skills and strategies - afirmam que "ter oportunidades suficientes para ensinar pode implicar encontrar oportunidades para aprender e adquirir conhecimentos [...], pode implicar ter oportunidades para desenvolver as qualidades pessoais [...] e implicar a criação de um ambiente de trabalho solidário [...]".

Na convicção de Woods (1990, p. 1), a abundância de oportunidades de aprendizagem sugere aos professores ficarem mais "à vontade para abordar os problemas mais puros do ensino, como promover a aprendizagem do aluno, de competências e conhecimentos relevantes e de valor".

A concordância destas considerações permitiu que Hargreaves (1998) e Day (2001) configurassem um quadro psicossocial que assenta particularmente na mobilização do pensamento e da acção dos professores. Porém, Morais e Medeiros (2007, p. 62) complementam este quadro, afirmando que o processo de desenvolvimento profissional do docente, como processo "interactivo, inacabado, dependente do indivíduo", é admitido, concomitantemente, como "dependente das possibilidades do meio, enquanto determinante na construção do seu saber e da sua pessoalidade".

Nesse sentido, segundo Sugrue (2004), para que o professor seja transformador do seu desenvolvimento profissional ao longo da carreira, isto é, para que a 
aprendizagem profissional aconteça na escola há a necessidade de ocorrerem determinadas condições, bem como de tempo e espaço propícios que permitam ao professor aceder facilmente à aprendizagem de (novas) competências.

Os trabalhos de Vonk e Schras (1987) também mostram as dificuldades experienciadas pelos professores em aprender na escola, devido a um conjunto de factores ambientais determinados externamente e outros específicos da escola, concluindo que todos gostavam de ensinar, mas que ser professor nas condições actuais é bastante oneroso, provocando um estresse contínuo e desgastante, que se reflete na sua auto-imagem.

Flores et al. (2009) referem a necessidade de apoiar e acompanhar os docentes ao longo da sua carreira enquanto fator importante na melhoria da qualidade da educação. Esta é uma estratégia formativa que o estudo realizado por Caetano durante os dois primeiros anos do presente milénio (Veiga Simão, Caetano \& Flores, 2005) também enfatiza. Do mesmo estudo depreendemos que, para além do apoio e do acompanhamento, o professor tem ainda a hipótese de colaborar "na elaboração de intervenções alternativas" e que, em clima de mudança, é importante "um tempo de integração para que se estabeleça uma relação entre a mudança e a continuidade" (VEIGA SIMÃO; CAETANO; FLORES, op cit, p. 180), ou seja, um tempo para a aprendizagem, para o desenvolvimento profissional contínuo, o que o nosso estudo revela não estar a acontecer no interior das nossas escolas.

\section{Metodologia e amostra}

Na nossa investigação, com professores do $1^{\circ}$ Ciclo do Ensino Básico (CEB) em Portugal, tivemos como principal finalidade identificar os elementos intervenientes no seu desenvolvimento profissional e as implicações que a legislação anteriormente referenciada teve no seu desenvolvimento e identidade profissional e na escola, tomando como referência os seguintes objetivos: i) identificar as perspectivas que os professores do $1^{\circ} \mathrm{CEB}$ têm dos documentos legislativos emanados recentemente; ii) identificar as experiências dos professores que marcam o seu desenvolvimento profissional; iii) conhecer as oportunidades de aprendizagem dos professores na escola.

A nossa investigação combina as abordagens quantitativa e qualitativa de investigação, com o intuito de procurarmos, por um lado, obter informações aprofundadas sobre a perspectiva dos professores e, por outro lado, recolher dados de um número significativo de professores que pudessem sustentar os dados obtidos junto do grupo mais restrito de informadores-chave. Optámos, assim, pelas narrativas orais (NO) e escritas (NE) e os grupos de discussão (GD), por um lado, e por outro lado, pela aplicação de um questionário (Q), ao qual obtivemos 249 respondentes, 
num total de 396 questionários distribuídos. Este estudo foi efectuado longitudinalmente, acompanhando os informadores-chave (oito professores) entre 2007 e 2010.

Neste texto faremos recurso a alguns dos resultados de natureza qualitativa tratados com recurso ao programa NVivo e à análise de conteúdo emergente $\mathrm{e}$ indutiva. Desta análise resultou uma estrutura categorial final, que reproduzimos parcialmente no ponto seguinte, com o objectivo de evidenciarmos os principais resultados aqui em discussão.

No quadro que se segue apresentamos as principais características sociodemográficas, que sistematizamos dos 249 professores participantes neste estudo:

\section{Quadro 1}

Caracterização sociodemográfica da amostra (percentagem)

\begin{tabular}{|c|c|c|c|c|c|c|c|c|c|c|c|c|c|}
\hline \multicolumn{2}{|c|}{ Sexo } & \multicolumn{4}{|c|}{ Grupos de Idade } & \multicolumn{4}{c|}{ Habilitações Académicas } & \multicolumn{4}{c|}{ Tempo de Serviço } \\
\hline F & M & Até 30 & $\mathbf{3 1 - 4 0}$ & $\mathbf{4 1 - 5 0}$ & +50 & Bac. & Lic. & Mest. & Espe. & Até 10 & $\mathbf{1 1 - 2 0}$ & $\mathbf{2 1 - 3 0}$ & + $\mathbf{3 0}$ \\
\hline 80,7 & 19,3 & 14,1 & 39,0 & 30,5 & 16,5 & 8,8 & 85,1 & 5,6 & 0,4 & 37,8 & 30,9 & 27,3 & 4,0 \\
\hline
\end{tabular}

Notas: Bac. (Bacharelato); Lic. (Licenciatura); Mest. (Mestrado) e Espe. (Especialização).

O Quadro 1 sistematiza as principais características dos professores do $1^{\mathrm{o}}$ CEB que constituíram a nossa amostra, as quais poderão ajudar na compreensão de alguns dos resultados do estudo que iremos explicitar em seguida. Referimo-nos, concretamente, às perceções dos professores relatadas nas narrativas biográficas escritas e orais recolhidas em duas fases (2008-2010) e nos três grupos de discussão formados para o efeito. Para além das percepções evidenciadas nos textos narrativos dos professores, apresentamos alguns dos resultados recolhidos através da aplicação de um questionário e das suas respostas a algumas das questões abertas dos mesmos.

\section{Trabalho docente, oportunidades de aprendizagem e desenvolvi- mento profissional: as experiências vividas pelos professores}

A análise das informações que obtivemos através das fontes já anteriormente referidas permitiu-nos identificar um conjunto de categorias e subcategorias de natureza indutiva e emergentes do discurso oral e escrito produzido pelos professores em contextos diversos, de modo a assegurarmos a triangulação dos métodos de recolha de informação. 
No Quadro 2, apresentamos a estrutura categorial final parcial das categorias e subcategorias que são mais relevantes para os conteúdos que procuramos evidenciar neste artigo, já que outras categorias e subcategorias foram identificadas na análise global dos dados recolhidos.

\section{Quadro 2}

A estrutura categorial final parcial: as categorias e as subcategorias reduzidas

\begin{tabular}{|c|c|}
\hline Categorias & Subcategorias \\
\hline $\begin{array}{l}\text { Desenvolvimento } \\
\text { profissional }\end{array}$ & 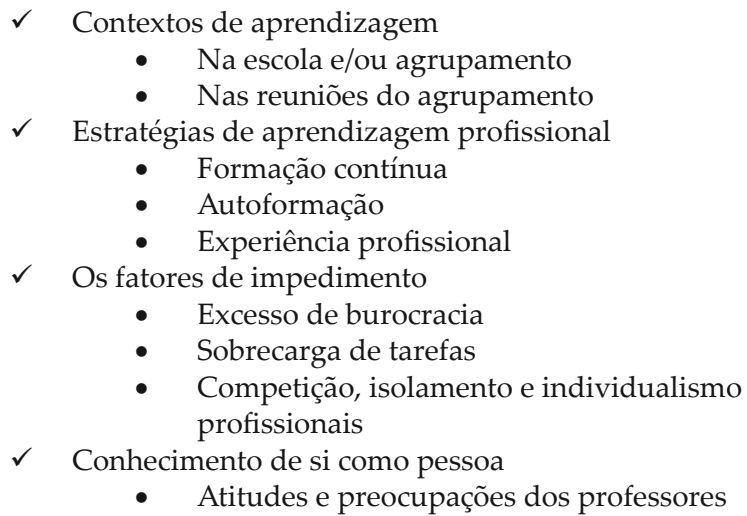 \\
\hline $\begin{array}{l}\text { Políticas educativas } \\
\text { e curriculares }\end{array}$ & 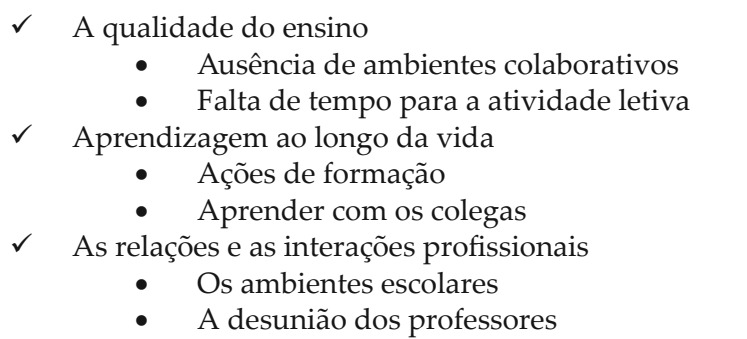 \\
\hline $\begin{array}{l}\text { Identidade } \\
\text { profissional }\end{array}$ & $\begin{array}{cc}\checkmark & \text { Reconhecimento profissional } \\
\checkmark & \text { Descredibilização da imagem do professor/escola } \\
\checkmark & \text { Identidade individual } \\
\checkmark & \bullet \quad \text { A imagem de si e do seu trabalho } \\
\checkmark & \text { Identidade coletiva } \\
& \bullet \quad \text { A imagem dos outros }\end{array}$ \\
\hline
\end{tabular}

Na discussão do significado da experiência na aprendizagem do adulto, Silva (2003, p. 58) sustenta que "as experiências vividas são um suporte importante" para a instigação do desenvolvimento profissional, e o reconhecimento dessas experiências vividas nos diferentes contextos recorre a uma interacção entre saberes teóricos 
e saberes práticos (MALGLAIVE, 1995) que estrutura o ciclo de aprendizagem e de desenvolvimento docente, como se pode observar na afirmação deste professor: "Porque são as minhas experiências profissionais que me impulsionam para o desenvolvimento profissional, tendo por base os interesses e as exigências dos alunos" (Q. 223).

Na sala de aula, as experiências dos professores centram-se fundamentalmente no processo de ensino e aprendizagem, mais propriamente na manutenção da disciplina, na investigação de diferentes métodos de ensino, nos resultados escolares e na auto-reflexão da prática pedagógica, como poderemos ler nas diferentes afirmações que se seguem.

“[...] em relação aos alunos, têm um comportamento cada vez mais horrível, não têm regras, não têm responsabilidade [...]". (Amélia, NO/2010)

“[...] há imensos métodos, já trabalhei no método global, analítico/sintético, método natural, portanto, diversas formas, este ano, como tenho a Isabel lá na escola, e ela trabalhou o método Jean Qui Rit, aproveitei para aprender [...]”. (Gabriela, NO/2010)

“[...] e que eu na altura já sabia o que eram bons resultados, mas mesmo assim eu 'massacrava-os', neste sentido: quero mais, quero mais, quero mais [...]". (Patrícia, NO/2010)

“[...] houve aulas que eu disse assim: - Ai, ao menos está aqui uma luz ao fundo do túnel, ainda bem que isto resultou hoje, será..., mas ainda fico sempre a pensar, será que eles perceberam mesmo?". (Patrícia, NO/2010)

De uma forma geral, na sala de aula, os professores vivem momentos de realização profissional fortalecendo a sua autoestima e imagem positiva do seu desempenho docente, o que influencia a construção permanente da sua identidade e estimula o profissionalismo, como evidenciam as seguintes afirmações:

“[...] eles leram, era uma poesia enorme [...] com imensos casos de leitura, e o que é certo, é que os miúdos leram aquilo tudo, estás a perceber? Claro, eu fiquei toda 'babada', toda contente $[\ldots] "$... (Gabriela, NO/2010)

“Significa que, afinal, nós somos queridos, quando eles têm boas notas, nós pensamos: alto! eu estou aqui a fazer qualquer coisa importante [...] e sinto-me feliz [...]". (Noémia, GD2)

Apesar de Estrela (2010) constatar que as experiências mais marcantes, vividas ao longo do percurso profissional, predominam em episódios referentes a turmas ou alunos, na nossa investigação os professores percepcionam, sem dúvida, as experiências relacionais na escola - com os pais, os colegas, os directores e a tutela como as mais marcantes e suportadas em sentimentos negativos, com impacto na(s) atitude(s) profissional(ais), emergindo a vontade de desistir de investir no trabalho docente de qualidade, pela falta de reconhecimento. A citação seguinte evidencia isto mesmo: 
Qualidade e trabalho docente: as experiências e oportunidades de aprendizagem...

“[...] os professores empenhados, desde sempre, sentem-se abandonados neste sistema pedindo reformas antecipadas, desistindo de investir na escola, no colectivo, desconfiando de tudo e de todos, parece que há sempre alguém que nos quer tramar. E eu que nunca senti nada disto!". (Amélia, NE/2008)

As experiências mais negativas vividas na escola pelos professores baseiam-se nas relações que se estabelecem entre os diferentes elementos da comunidade educativa, mais propriamente nas relações que se instituem entre professores, entre professores e pais dos alunos e entre professores e órgãos de gestão. Para além destas relações, os professores experienciam outras com o Ministério da Educação e com a sociedade em geral, que dão conta de atos de atribuição distanciados dos atos de pertença que, mais uma vez, acentuam uma identidade social marcada pela dualidade (DUBAR, 1997).

As referências que transcrevemos a seguir dão conta desta dualidade e falta de reconhecimento pelos diferentes atores e como os docentes interagem no seu trabalho quotidiano:

\footnotetext{
"Nascem novas relações entre os professores, mas muito confusas, numa base de desconfiança e desmotivação". (Catarina, NE/2008)

“[...] dizer ou fazer alguma coisa a algum menino, porque também o podemos 'ferir', podemos dizer alguma coisa que ele não goste, então o paizinho vai reclamar, porque o professor teve uma atitude incorrecta, chamou-o à atenção e o menino ficou inibido, já nem quer ir à escola $[\ldots]^{\prime \prime}$. (Salvador, GD1)

“[...] a nível de agrupamentos a gente quando vê alguém o Vice, o Assessor eu, por exemplo, até começo a ficar já mal disposta [...]". (Fátima, GD3)

"[...] total desconhecimento e desrespeito que o Ministério da Educação tem demonstrado pela docência". (Q. 182)

“Não vejo reconhecimento, por parte da sociedade que, infelizmente, vê a classe docente de forma distorcida". (Q. 169)
}

$\mathrm{Na}$ escola, para além das experiências de relacionamento, similarmente os professores vivem as de reconhecimento pelos outros que, segundo Silva (2007, p. 160), é "um aspecto fundamental na satisfação profissional e particularmente mobilizador no trabalho". Na convicção dos professores inquiridos, a ausência atual desse reconhecimento é geradora de stresse, cansaço, ansiedade e incompreensão na profissão:

“[...] o reconhecimento do papel do professor e é aí que está tudo, nós trabalhamos, trabalhamos, trabalhamos mas ninguém reconhece, e pode ser que eu esteja enganado, mas a percepção que tenho é que ninguém reconhece o nosso trabalho, e quando digo ninguém, falo desde [...] os encarregados de educação e as pessoas que trabalham connosco, na comunidade educativa [...]". (Manuel, GD3) 
Finalmente, em situação de formação contínua, os docentes declaram perpassar momentos de partilha e reflexão de experiências pedagógicas, naturalmente, quando a acção de formação é de qualidade e responde às necessidades de desenvolvimento dos professores e o formador revela competências para a tarefa que desempenha, conforme refere Diogo (NO/2010): “Nesta formação de Ciências [...] conseguimos partilhar o suficiente para sabermos o que é que tu fizeste e o que é que eu não fiz, mas isso tem a ver com a nossa formadora, que é de facto, consegue-nos pôr ali a funcionar".

No entanto, podemos perceber que há alguma dificuldade em concretizar na escola, nas práticas quotidianas com os colegas, os saberes experienciados e partilhados nas diferentes situações, por requererem condições - o tempo, a confiança e a motivação - que se encontram praticamente ausentes nos contextos educativos atuais, como enunciam as seguintes afirmações:

“[...] com menos tempo para me dedicar à formação profissional que acho importante $[\ldots]^{\prime \prime} .(\mathrm{Q} .106)$

"As leis que estão neste momento em vigor, relativamente à educação fazem-me perder a confiança num futuro melhor". (Q. 49)

“No meio desta confusão é difícil estar motivado e confiar em alguma coisa". (Q. 151)

Podemos perceber que existe um conjunto de experiências preponderantemente positivas - na sala de aula e nos espaços de formação dos professores - e um conjunto de experiências predominantemente negativas - que advêm das políticas educativas atuais no âmbito da estrutura da carreira docente, das novas exigências profissionais, das relações (inter)pessoais e do sucesso educativo.

Estas experiências são vividas pelo grupo de professores inquiridos, independentemente da etapa da carreira docente em que se encontram, e têm efeitos negativos no desenvolvimento profissional e na (re)construção da(s) identidade(s), pelo efeito desmobilizador que podem provocar: "[...] tenho pena que me estejam a cortar as pernas, a liberdade de ser uma professora feliz e motivada para o meu trabalho, tal como fui no início da minha carreira pelas experiências enriquecedoras que tive oportunidade de viver" (Sónia, NE/2008).

Dessa forma, os docentes sentem-se em grande medida fragilizados e, com frequência, incapazes para ultrapassar o cansaço profissional (e pessoal) associado às sucessivas mudanças na educação, porque as experiências profissionais reconhecidas como importantes para o seu desenvolvimento profissional, nomeadamente em contexto de formação e de sala de aula, não são suficientemente sustentáveis para conseguir superar as dificuldades relacionais na escola e a ausência de reconhecimento profissional. Esta insustentabilidade emerge, segundo os professores 
inquiridos, sobretudo, da fraca qualidade da formação contínua e da ausência de igualdade no acesso às oportunidades de aprendizagem, condicionando, em parte, a dinâmica das práticas reflexivas e o processo colaborativo na escola.

Nas investigações de Huberman (1989), os professores que viveram (ou vivem) experiências de "experimentação" ou "renovação" com os colegas na sala de aula e/ou na escola consideraram-nas como as mais emocionantes e formativas da (sua) carreira: "[...] nunca mais tive oportunidade de trabalhar com uma equipa tão dinâmica, tão coesa e eficaz e tão amiga e solidária, como aquele grupo de colegas [...] uma equipa de trabalho como a que existiu naquela escola; faz toda a diferença na vida de um professor e de uma escola" (Carolina, NO/07).

Atendendo à ideia de que os contextos de trabalho são dinâmicos, Guskey (1995) sugere uma "combinação ideal" entre a aprendizagem profissional e as oportunidades, ao que Day (2004) acrescenta que, no decurso da carreira docente, a escola deve participar na criação de oportunidades sustentadas na diversificação de atividades, tanto dentro como fora da instituição.

Dessa forma, trabalhar em grupos formais, por exemplo nas reuniões de escola/agrupamento, seria uma oportunidade de encorajar a divulgação, a partilha e a colaboração, derrubando potenciais barreiras à participação em todas as formas de prática reflexiva (DAY, 2004; HERDEIRO, 2010).

Contudo, os professores sentem que este espaço de aprendizagem formal está subaproveitado, não incentivando à aprendizagem profissional, devido, essencialmente, ao carácter burocrático imposto, ao tempo de que dispõem e que sentem que foi francamente desperdiçado e, simultaneamente, instigador de desgaste profissional, como se pode observar pelas referências seguintes:

\footnotetext{
“[...] se essas reuniões fossem a nível de partilha dentro da escola, eu acho que se poderia aprender muito mais coisas". (Ruivo, GD3)

“[...] como frisei há pouco, a nível de reuniões, que são inúmeras, todos os meses, quase, há reuniões, às vezes sinto que o que vamos lá fazer e o que resolvemos nessas reuniões é essencialmente parte burocrática [...]". (Elsa, NO/2010)

“[...] às horas que a gente passa nas reuniões [...] e que isso me torna um cansaço enorme que por vezes não tenho o rendimento que gostaria de ter na minha sala de aula". (Rita, GD3)
}

A estas razões, os professores acrescentam a formação e a capacidade de coordenação dos responsáveis pela dinamização das reuniões, desvalorizando as temáticas pedagógicas e o direito de participação num ambiente reflexivo e de confiança, caracterizadas pelos professores como: “[...] verdadeiros monólogos [...]" (Manuel,GD3), “[...] onde nós estamos e pouco se aprende, portanto, aquilo que é mais importante, a nossa prática, não é discutido [...]” (Elsa, NO/2010). 
Todavia, para além desta oportunidade de aprendizagem, os professores referem outras presentes na escola, como a frequência de acções de formação, a coordenação e participação em projectos e as experiências pedagógicas desenvolvidas na sala de aula.

Por seu turno, as instituições superiores oferecem aos docentes, para além de acções de formação, cursos de pós-graduação e especializações em diversas áreas, correspondendo à necessidade, sempre renovada, de fazer face a "necessidades conjunturais e localizadas, quer sejam de ordem funcional ou individual" (MALGLAIVE, 1995, p. 24) e, preferencialmente, centrada na escola (DAY, 2001) e nas necessidades individuais dos professores (PACHECO, 1995).

Mediante as oportunidades de aprendizagem facultadas, os professores sentem que as mesmas emergem num plano diferenciado entre os docentes de uma mesma instituição: "As oportunidades de desenvolvimento não são iguais para todos" (Q. 144). Ou seja, os professores do $1^{\circ}$ CEB percepcionam que "[...] não têm as mesmas oportunidades" (Q. 145) e as que existem são atribuídas, preferencialmente, aos docentes dos outros ciclos ou níveis de ensino: “[...] a nível de agrupamento são poucas as solicitações e os projectos para os quais estamos envolvidos" (Elsa, NO/2010).

Da mesma forma, a oferta de ações de formação não responde às necessidades dos docentes na escola, tanto pela qualidade como pela quantidade (GARCÍA, 1999). A imposição temática das ações de formação pelo Ministério da Educação é uma constante, diminuindo a margem de escolha dos professores, como nos refere a Elsa na sua narrativa oral:

“[...] existe um leque pouco variado de acções de formação [...] e que podem não ir ao encontro do interesse dos docentes e das suas necessidades momentâneas e contextualizadas, como é o caso do excesso de oferta de formação em TIC e das Bibliotecas Escolares $[\ldots]$ que, neste momento, isso não é o que me aflige [...]". (Elsa, NO/2010)

Para além dos critérios referidos, o tempo de serviço que os professores têm na escola/agrupamento também é uma referência atendida pelos diretores, quando pretendem distribuir as oportunidades de desenvolvimento pelos profissionais da instituição. Assim, “[...] iniciar um projecto num agrupamento, em que estás há pouco tempo, neste caso, no meu, em que estou só há um ano, nem pensar [...]" (Patrícia, NO/2010), porque os projectos que já existem nos agrupamentos, “[...] geralmente, são dinamizados por pessoas que já estão há muito tempo no agrupamento (...)"(ibid.) e que já pertencem ao círculo de amigos dos que têm o poder de decisão: “[...] portanto, já os conhecem, já sabem para onde é que hão-de ir, e que pessoas é que devem escolher [...]" (ibid.). Com certeza que esta oportunidade garante aos seus líderes/coordenadores uma dupla satisfação profissional: ter sido escolhido pelo órgão directivo e ver reconhecido o seu trabalho publicamente, face ao trabalho 
dos restantes colegas: “[...] só alguns docentes, os que fazem directamente parte do projecto, são reconhecidos, os restantes professores diluem-se" (Q. 242), influenciando as identidades profissionais docentes.

Dessa forma, os professores reconhecem a existência de oportunidades na escola, mas também apontam muitos constrangimentos que operam como fatores inibidores da construção de uma carreira docente aliciante: "[...] pouco foi a oportunidade que me deram [...]" (Elsa, NO/2010).

Neste contexto, os professores mais jovens resignam-se (ou sentem-se na obrigação de o fazer) à ideia de que as oportunidades sejam entregues aos colegas "mais velhos" pelo reconhecimento da pouca experiência profissional que ainda possuem. Contudo, a desigualdade de oportunidades é criticada com maior intensidade pelos professores que se situam a meio da carreira docente ou aproximadamente: "A nossa oportunidade nunca mais chega!" (Elsa, NO/2010), argumentando que a sua experiência e competência profissionais são mais do que suficientes para (co)responder às expectativas dos diretores na coordenação e/ou orientação de projetos de vária natureza. Porém, raramente são solicitados, em detrimento dos colegas que se encontram há mais tempo na escola/agrupamento, entre outros critérios referidos anteriormente, provocando desmotivação profissional, com repercussões no trabalho docente: "Esta situação gera nos professores uma desmotivação que se reflecte impreterivelmente na sua prática docente" (Elsa, NO/201).

De uma forma geral, esta imagem de escola estagnada, ou mesmo empobrecida, no entender de Day (2004, p. 162) incita a que "os professores se sintam verdadeiramente desencorajados para melhorar a sua prática", dispersando-os para outros aspetos da carreira docente, como a discussão do processo de avaliação do desempenho docente, "[...] os professores passam mais tempo preocupados com a questão da avaliação do que com a troca de ideias [...]"(Catarina, NE/2008). Este dispersar de atenções provoca algum desinteresse no processo de ensino e aprendizagem, " [...] sobretudo, acho que veio penalizar um bocadinho, embora seja involuntário, [o trabalho] com as crianças, eu sinto isso; eu, muitas vezes, paro um segundo e digo '- Isto não devia ser assim, mas'..." (Fátima, GD3), e estimula a acumulação de preocupações emocionais como a culpa, característica frequentemente decorrente das exigências de prestação de contas e dos controlos burocráticos (HARGREAVES, 1998).

\section{Oportunidades de aprendizagem e de desenvolvimento profissio- nal nas escolas: realidade ou utopia?}

O objetivo do presente artigo é refletir sobre o desígnio das políticas educativas europeias - alcançar um ensino de qualidade que promova o sucesso dos alunos -, 
questionando os propósitos e as implicações dos diplomas legislativos que o governo português traçou para promover o desenvolvimento profissional com consequências na qualidade do trabalho docente. Neste âmbito, é fundamental conhecer as experiências e as oportunidades de aprendizagem que as escolas oferecem aos professores, para que se desenvolvam profissionalmente e sejam capazes de construir um trabalho de qualidade na sala de aula.

Globalmente, concluímos que os propósitos exarados nos documentos legislativos provocam situações frustrantes nas escolas, principalmente devido à ausência de experiências enriquecedoras e de promoção de momentos de aprendizagem docente numa cultura colaborativa, bem como às débeis relações socioprofissionais, apesar da evidente relevância delineada pelos especialistas da educação (DEAN, 1991; SMYLIE, 1995; GARCÍA, 1999; DAY, 2001) nestes domínios.

Por um lado, os estudos de Day (2001) alicerçam o desenvolvimento profissional dos professores nas diversas experiências de aprendizagem (naturais, planeadas e conscientes), implicando, por sua vez, a existência de dispositivos e contextos que levem o professor a uma atitude consequente de investimento profissional.

Todavia, na(s) voz(es) dos professores participantes, as experiências de aprendizagem vividas por eles na escola baseiam-se nas difíceis relações que se estabelecem entre os diferentes elementos da comunidade educativa, mais propriamente nas relações que se instituem entre professores, entre os professores e os pais dos alunos e entre os professores e os órgãos de gestão. É de destacar que estas relações se (re) constroem na escola sustentadas em alicerces baseados na desconfiança e na insegurança socioprofissionais que, a par da ausência de reconhecimento profissional, são geradores de estresse, cansaço, ansiedade e incompreensão na profissão, comprometendo a paixão pelo ensino, o trabalho docente de qualidade e, consequentemente, $\mathrm{o}$ sucesso dos alunos.

Por outro lado, a promoção da aprendizagem no local de trabalho é reforçada por Smylie (1995), ao salientar as oportunidades dos indivíduos para trabalhar e aprender com os outros numa base contínua, acreditando que a aprendizagem pode ser melhorada através da partilha com os outros, particularmente com aqueles que possuem conhecimentos e experiências diferentes.

Contudo, os professores questionados alertam para o facto de as oportunidades de aprendizagem facultadas na escola emergirem de um plano diferenciado entre os docentes de uma mesma instituição, garantindo que as mesmas são atribuídas, preferencialmente, aos docentes dos outros ciclos ou níveis de ensino.

Desse modo, podemos inferir que a atual política educativa interfere negativamente na motivação para desenvolver um trabalho docente profícuo, particularmente a ausência de reconhecimento e valorização da imagem do professor no 
contexto social, com consequências na prática pedagógica, nas relações entre pares e na autoestima e identidade profissional.

Neste contexto de desmotivação profissional docente, a mudança não passará de uma forma de acção política simbólica, desprovida de qualquer empenhamento ou sentido de posse pessoal ou interno à instituição, porque as reformas educativas são bem-sucedidas quando os professores as encaram como fontes de inspiração e, simultaneamente, as entendem como elementos necessários à própria reforma.

\section{Referências}

DARLING-HAMMOND, L. Reconhecer e potenciar a eficácia docente: guia para decisores políticos. In: FLORES, M.A. (Org.). A avaliação de professores numa perspectiva internacional: sentidos e implicações. Porto: Areal, 2010. p. 197-235.

DAY, C. Desenvolvimento profissional de professores: os desafios da aprendizagem permanente. Porto: Porto, 2001.

DAY, C. A paixão pelo ensino. Porto: Porto, 2004.

DAY, C.; SACHS, J. Professionalism, performativity and empowerment: discourses in the politics and purposes of continuing professional development. In: DAY, C.; SACHS, J. (Org.). International handbook on the continuing of teachers. Maidenhead: Birks; Open University, 2004. p. 3-32.

DEAN, J. Professional development in school. Milton Keynes: Open University, 1991.

DUBAR, C. A socialização: construção das identidades sociais e profissionais. Porto: Porto, 1997.

ESTRELA, M.T. Profissão docente: dimensões afectivas e éticas. Porto: Areal, 2010.

FLORES, M.A. et al. Possibilidades e desafios da aprendizagem em contexto de trabalho: um estudo internacional. In: FLORES, A.; VEIGA SIMÃO, A.M. (Org.). Aprendizagem e desenvolvimento profissional de professores: contextos e perspectivas. Porto: Pedago, 2009. p. 119-151.

GARCÍA, C.M. Formação de professores: para uma mudança educativa. Porto: Porto, 1999.

GONÇALVES, J.A. Ser professora do $1^{\underline{0}}$ Ciclo: uma carreira em análise. 2000. Tese (Doutorado em Educação) - Faculdade de Psicologia e de Ciências da Educação, Universidade de Lisboa, Lisboa.

GUSKEY, T. Professional development in education: in search of the optimal mix. 
In: GUSKEY, T.; HUBERMAN, M. (Ed.). Professional development in education: new paradigms e practices. New York: Teachers College, 1995. p. 114-132.

HARGREAVES, A. Os professores em tempos de mudança: o trabalho e a cultura dos professores na Idade Pós-Moderna. Lisboa: McGraw-Hill, 1998.

HARGREAVES, A.; FULLAN, M. Introduction. In: HARGREAVES, A.; FULLAN, M. (Org.). Understanding teacher development. New York: Teachers College, 1992. p. 1-19.

HERDEIRO, R. Trabalho docente e desenvolvimento profissional: narrativas de professores. Lisboa: Chiado, 2010.

HUBERMAN, M. La vie des enseignants: évolution et bilan d'une profession. Lausanne: Delachaux et Niestlé, 1989.

KELCHERMANS, G. O comprometimento profissional para além do contracto: autocompreensão, vulnerabilidade e reflexão dos professores. In: FLORES, M.A.; VEIGA SIMÃO, A.M. (Org.). Aprendizagem e desenvolvimento profissional de professores: contextos e perspectivas. Mangualde: Pedago, 2009. p. 61-98.

MALGLAIVE, G. Ensinar adultos: trabalho e pedagogia. Porto: Porto, 1995.

MARCHESI, Á.; MARTÍN, E. Qualidade do ensino em tempos de mudança. Porto Alegre: Artmed, 2003.

MONTEIRO, A.R. Qualidade, profissionalidade e deontologia na educação. Porto: Porto, 2008.

MORAIS, F.; MEDEIROS, T. Desenvolvimento profissional do professor: a chave do problema? Açores: Universidade dos Açores, 2007.

ORGANIZAÇÃO PARA A COOPERAÇÃO E DESENVOLVIMENTO ECONÓMICO (OCDE). As escolas e a qualidade. Porto: ASA, 1992.

PACHECO, J.A. Formação de professores: teoria e praxis. Braga: Universidade do Minho, 1995.

SILVA, A.M. Formação, percursos e identidades. Coimbra: Quarteto, 2003.

SILVA, A.M. Ser professor(a): dinâmicas identitárias e desenvolvimento profissional. In: FLORES, M.A.; VIANA, I. (Org.). Profissionalismo docente em transição: as identidades dos professores em tempos de mudança. Braga: Universidade do Minho, 2007. p. 155-163.

SMYLIE, M.A. Teacher learning in the workplace: implications for school reform. In: GUSKEY, T.; HUBERMAN, M. (Ed.). Professional development in education: new paradigms e practices. New York: Teachers College, 1995. p. 92-109. 
SUGRUE, C. Rhetoric's and realities of CPD across Europe: from cacophony towards coherence? In: DAY, C.; SACHS J. (Org.). International handbook on the continuing professional development of teachers. Maidenhead: Birks; Open University, 2004. p. 67-93.

VEIGA SIMÃO, A.M.; CAETANO, A.P.; FLORES, M.A. Contextos e processos de mudança dos professores: uma proposta de modelo. Educação $\mathcal{E}$ Sociedade, Campinas, v. 26, n. 90, p. 173-188, jan./abr. 2005.

VONK, J.; SCHRAS, G. From beginning to experienced teacher: a study of the professional development of teachers during their first years of service. European Journal of Teacher Education, Abingdon, v. 10, n.1, p. 95-110, 1987.

WOODS, P. Teacher skills and strategies. London: Falmer, 1990.

\section{Legislação consultada}

Decreto-Lei n. 15/2007, de 19 de janeiro de 2007.

Decreto Regulamentar n. 2/2008, de 10 de janeiro de 2008.

Recebido em 13 de fevereiro de 2012.

Aprovado em 20 de agosto de 2013. 